\title{
Sputum endothelin-1 is increased in cystic fibrosis and chronic obstructive pulmonary disease
}

\author{
G.W. Chalmers*, K.J. Macleod**, S. Sriram*, L.J. Thomson*, C. McSharry**, \\ B.H.R. Stack*, N.C. Thomson*
}

\begin{abstract}
Sputum endothelin-1 is increased in cystic fibrosis and chronic obstructive pulmonary disease. G.W. Chalmers, K.J. Macleod, S. Sriram, L.J. Thomson, C. McSharry, B.H.R. Stack, N.C. Thomson. C ERS Journals Ltd 1999.

ABSTRACT: Many patients with cystic fibrosis (CF) have airflow obstruction, with peribronchial and peribronchiolar fibrosis. Endothelin (ET)-1 is a potent bronchoconstrictor with mitogenic activity for airway smooth muscle. Do the levels of ET-1 in sputum support the putative role of ET-1 in contributing to airway remodelling with airflow obstruction in CF?

The levels of ET-1 in plasma, saliva and sputum from 12 adult patients with CF not in exacerbation (spontaneous sputum), 17 normal control subjects (induced sputum) and as an additional control population, nine patients with stable chronic obstructive pulmonary disease (COPD) (seven spontaneous sputum) were measured. Total and differential sputum cell counts were performed.

Median (interquartile range) sputum ET-1 level was elevated in CF (77.6 (29.0122.8) $\left.\mathrm{pg} \cdot \mathrm{mL}^{-1}\right)$ compared to normal subjects $\left(6.00(2.8-14.8) \mathrm{pg} \cdot \mathrm{mL}^{-1}\right)$ and COPD $\left(16.4(6.8-38.2) \mathrm{pg} \cdot \mathrm{mL}^{-1}\right)$, and in COPD compared to normal subjects. There was a slight elevation of plasma ET-1 level in CF (5.3 (3.2-6.0) pg. $\left.\mathrm{mL}^{-1}\right)$ compared to normal subjects $\left(3.1(1.7-4.4) \mathrm{pg} \cdot \mathrm{mL}^{-1}\right)$ and COPD $\left(3.3(2.7-4.2) \mathrm{pg} \cdot \mathrm{mL}^{-1}\right)$. Sputum and saliva ET-1 levels were significantly higher than plasma levels in all groups, suggesting local production or release in the respiratory tract. Sputum differential cell counts revealed pronounced neutrophilia in CF and COPD compared to normal subjects.

Sputum endothelin-1 concentrations are elevated in cystic fibrosis sputum compared to chronic obstructive pulmonary disease, and in cystic fibrosis and chronic obstructive pulmonary disease compared to normal subjects. The role of endothelin-1 in contributing to airflow obstruction through bronchoconstriction and mitogenesis in cystic fibrosis needs now to be explored.

Eur Respir J 1999; 13: 1288-1292.
\end{abstract}

\begin{abstract}
*Depts of Respiratory Medicine, West of Scotland Adult Cystic Fibrosis Unit, and **Immunology, West Glasgow Hospitals University NHS Trust, Western Infirmary, Glasgow, UK
\end{abstract}

\section{Correspondence: G.W. Chalmers}

Dept of Respiratory Medicine

West Glasgow Hospitals University NHS

Trust

1053 Great Western Road

Glasgow G12 0YN

UK

\section{Fax: 441412113464}

Keywords: Chronic obstructive pulmonary disease

cystic fibrosis

endothelin-1

sputum

\section{Received: October 301997}

Accepted after revision January 311999

This study was supported by grants from the National Asthma Campaign, UK (G.W. Chalmers) and the Chest Heart \& Stroke Association of Scotland (L.J. Thompson and K.J. Macleod).
Cystic fibrosis (CF) is characterized by recurrent infection leading to the development of bronchiectasis, and by peribronchial and peribronchiolar fibrosis leading to airway remodelling with airflow obstruction. Sputum neutrophilia is characteristic. While most patients with $\mathrm{CF}$ will, during the course of their disease, demonstrate a variable degree of reversibility to bronchodilators [1], progression to fixed airflow obstruction with associated secondary fibrosis is expected. Cell proliferation rates may be very high in CF airways [2], although the growth factors which may be associated with cellular proliferation in $\mathrm{CF}$ remain to be fully characterized.

Endothelin (ET)-1 is a vasoactive 21-amino-acid peptide which is produced by human bronchial epithelial cells [3]. ET-1 produces prolonged and potent bronchoconstriction in asthma [4], and has mitogenic properties, with animal studies indicating a role in the proliferation of cultured airway smooth muscle cells [5] and airway epithelial cells [6]. ET-1 also acts as a comitogen with a number of other growth factors, and induces the expression of pro-inflammatory and profibrotic factors including tumour necrosis factor (TNF)- $\alpha$ [7] and fibronectin [8].
The objectives of the study were to establish whether ET-1 could be measured in the sputum of CF patients, to compare the levels of ET-1 in sputum, saliva and plasma, and to compare the levels of ET-1 in CF patients, patients with chronic obstructive pulmonary disease (COPD) (chosen as an additional control group because COPD is also characterized by sputum neutrophilia) and normal subjects.

\section{Methods}

\section{Subjects}

Twelve CF patients (seven male, five female) attending the West of Scotland Adult Cystic Fibrosis Unit were studied, in comparison with 17 healthy volunteers (10 male, seven female), and nine subjects with COPD (two male, seven female) (table 1). None of the CF patients or healthy subjects were smokers. Informed written consent was obtained from all subjects, and the study was approved by the West Ethics Committee, West Glasgow Hospitals University NHS Trust. 
Table 1. - Demographic lung function and pulmonary therapy data from normal volunteers and from patients with cystic fibrosis or chronic obstructive pulmonary disease (COPD)

\begin{tabular}{|c|c|c|c|c|c|c|}
\hline $\begin{array}{l}\text { Subject } \\
\text { No. }\end{array}$ & $\begin{array}{l}\text { Age } \\
\text { yrs }\end{array}$ & Sex & $\begin{array}{c}\text { FEV1 } \\
\text { L }\end{array}$ & $\begin{array}{l}\text { FEV1 } \\
\% \text { pred }\end{array}$ & $\begin{array}{l}\text { Cigarette } \\
\text { pack-yrs }\end{array}$ & Pulmonary therapy \\
\hline \multicolumn{7}{|c|}{ Normal volunteers* $(n=17)$} \\
\hline Mean & 31.8 & $10 \mathrm{M} / 7 \mathrm{~F}$ & 3.9 & 99.2 & None & None \\
\hline $\mathrm{SD}$ & 8.8 & & 1.1 & 11.4 & & \\
\hline \multicolumn{7}{|c|}{ Cystic fibrosis } \\
\hline 1 & 27 & $\mathrm{~F}$ & 0.60 & 20 & None & Ipr; Pred 20; DNAse \\
\hline 2 & 28 & M & 0.74 & 19 & None & DNAse \\
\hline 3 & 22 & M & 0.99 & 24 & None & DNAse \\
\hline 4 & 16 & M & 2.30 & 59 & None & None \\
\hline 5 & 16 & M & 2.64 & 74 & None & S; Bud 1200 \\
\hline 6 & 23 & $\mathrm{~F}$ & 1.70 & 54 & None & None \\
\hline 7 & 36 & M & 0.70 & 21 & None & $\mathrm{S} ; \mathrm{BDP} ; 1000 ; \mathrm{Ox}$ \\
\hline 8 & 16 & $\mathrm{~F}$ & 0.95 & 38 & None & Terb \\
\hline 9 & 17 & $\mathrm{~F}$ & 2.05 & 64 & None & $\mathrm{S} ;$ Vol 16 \\
\hline 10 & 18 & $\mathrm{~F}$ & 1.50 & 53 & None & Terb; Bud 1600; Sm; DNAse \\
\hline 11 & 21 & M & 1.05 & 25 & None & $\mathrm{S} ; \mathrm{BDP} 1000$ \\
\hline 12 & 19 & M & 2.92 & 79 & None & Terb \\
\hline Mean & $21.6^{+}$ & $7 \mathrm{M} / 5 \mathrm{~F}$ & $1.5^{+}$ & $44^{+}$ & & \\
\hline $\mathrm{SD}$ & 6.1 & & 0.8 & 22 & & \\
\hline \multicolumn{7}{|l|}{ COPD } \\
\hline 1 & 58 & $\mathrm{~F}$ & 0.65 & 31 & 80 & S; Sm; BDP 1000 \\
\hline 2 & 64 & $\mathrm{~F}$ & 0.53 & 25 & 60 & $\mathrm{~S}$ \\
\hline 3 & 56 & $\mathrm{~F}$ & 0.74 & 30 & 40 & S; Ipr; BDP 1000; Th \\
\hline 4 & 56 & $\mathrm{~F}$ & 0.78 & 30 & 45 & S; BDP 800 \\
\hline 5 & 57 & $\mathrm{~F}$ & 0.64 & 26 & 40 & $\mathrm{~S} ; \mathrm{Sm} ; \mathrm{BDP} 1000$ \\
\hline 6 & 67 & $\mathrm{~F}$ & 0.83 & 34 & 50 & S; BDP 800 \\
\hline 7 & 73 & M & 0.42 & 16 & 50 & S; Sm; BDP 1000 \\
\hline 8 & 49 & $\mathrm{~F}$ & 0.75 & 33 & 30 & S; BDP 800 \\
\hline 9 & 54 & M & 0.60 & 17 & 60 & $\mathrm{~S} ; \mathrm{Sm}$ \\
\hline Mean & $59.3^{+}$ & $2 \mathrm{M} / 7 \mathrm{~F}$ & $0.66^{+, \#}$ & $26.9^{+, \#}$ & 50.6 & \\
\hline SD & 7.4 & & 0.1 & 6.6 & 14.7 & \\
\hline
\end{tabular}

*: summary data only. FEV1: forced expiratory volume in one second; M: male; F: female; Ipr: ipratropium bromide 2 mg daily, nebulized; Pred: prednisolone daily dose in mg; DNAse: recombinant human DNAse; S: inhaled salbutamol $200 \mu \mathrm{g}$ p.r.n.; Bud: budesonide daily dose in $\mu \mathrm{g}$; BDP: beclomethasone dipropionate daily dose in $\mu \mathrm{g}$; Ox: oxitropium bromide $200 \mu \mathrm{g}$ t.i.d.; Terb: terbutaline $0.5 \mathrm{mg}$ p.r.n.; Vol: tablet salbutamol daily dose in $\mathrm{mg}$; Sm: salmeterol $100 \mu \mathrm{g}$ b.i.d.; Th: theophylline $500 \mathrm{mg}$ daily. ${ }^{+}: \mathrm{p}<0.01$ versus normal subjects; : $\mathrm{p}<0.01$ versus cystic fibrosis patients.

\section{Protocol}

The study involved a single visit to the unit for consent and to obtain the samples of blood, sputum and saliva. Spontaneous sputum samples were obtained from the CF patients, and sputum induction using 3\% saline was performed on the normal subjects. Spontaneous sputum was obtained from seven of the COPD subjects and sputum induction performed on the remaining two.

\section{Laboratory processing}

Sputum plugs were selected (minimum $50 \mathrm{mg}$ ) to minimize salivary contamination and were split into two; one half was incubated for $20 \mathrm{~min}$ with fresh dithiothreitol (DTT) (Sigma UK Ltd., Poole, UK) in a balanced salt solution and used for cell counts, and the other half centrifuged $(15 \mathrm{~min}$ at $16,000 \times g)$, without treatment with DTT, for ET-1 assay (DTT altered the standard curve of ET-1). Samples from CF patients were incubated for $10 \mathrm{~min}$ with recombinant deoxyribonuclease (DNAse) $\left(50 \mu \mathrm{g} \cdot \mathrm{mL}^{-1}\right.$; Genentech Inc., San Francisco, CA, USA) to reduce the viscosity of the CF sputum, caused by its high deoxyribonucleic acid content (DNAse did not alter the ET-1 standard curve). Samples were filtered through a $50-\mu \mathrm{m}$ mesh
(R. Cadoch \& Sons, London, UK). Differential cell counts (Giemsa-stained) were expressed after exclusion of squamous cells, which were taken to represent salivary contamination. The numbers of bronchial epithelial cells were in general very low $(<2 \%)$, and were excluded from cell counts. ET-1 was assayed using a radioimmunoassay (RIA) (Nichols Institute Diagnostics Ltd., San Juan Capistrano, CA, USA) following extraction using C-18 cartridges (Sep-pak+; Waters Ltd., Watford, UK), both according to manufacturers instructions. Assays were performed in duplicate and the mean value used for analysis. Recovery was assessed by spiking samples with ET-1, followed by RIA as above.

\section{Statistical analysis}

Results are expressed as median and interquartile range unless otherwise specified. Nonparametric statistical analysis was used to compare cell counts and ET-1 concentrations, (Mann-Whitney U-test) using a software package (Minitab Statistical Software; Minitab Inc., State College, PA, USA) on an Apple Macintosh desktop computer (Apple Computer Inc., Cupertino, CA, USA). Significance was accepted at the $95 \%$ level. 


\section{Results}

\section{Patient demographics}

A comparison of demographic factors revealed that the $\mathrm{CF}$ patients were younger than the normal subjects and COPD patients, and that both CF and COPD patients had lower baseline spirometry values than normal subjects, with a mean \pm SD forced expiratory volume in one second (FEV1) of $44.2 \pm 22,26.9 \pm 6.6$, and $98.8 \pm 9.66 \%$ predicted respectively (table 1 ).

\section{Sputum cell counts}

Absolute and relative sputum cell counts were expressed after exclusion of squamous and bronchial epithelial cells and are summarized in table 2. Absolute and relative sputum neutrophilia were present in both CF and COPD patients compared with normal subjects, with neutrophil counts in CF exceeding those in COPD. There was a corresponding reduction in relative macrophage numbers in CF and COPD patients compared with normal subjects. There was a small but significant increase in eosinophil counts in COPD patients compared with normal subjects.

\section{Endothelin-1}

Assay. The mean recovery of ET-1 from sputum samples was $68 \%(n=2)$ and the coefficient of variation for the ET-1 assay in sputum was $11.4 \%$. DNAse had no effect on the ET-1 standard curve.

Plasma and saliva endothelin-1. Levels of ET-1 were examined in the plasma of all normal subjects and COPD patients and 10 of the CF patients, and in the saliva from all COPD patients, $10 \mathrm{CF}$ patients and a subgroup of eight of the normal subjects. Plasma levels were mildly elevated in $\mathrm{CF}$ compared to normal subjects (median (interquartile range) $5.3(3.2-6.0)$ versus $\left.3.1(1.7-4.4) \mathrm{pg} \cdot \mathrm{mL}^{-1}\right)$, but did not reach significance against COPD (3.3 (2.7-4.2) $\mathrm{pg} \cdot \mathrm{mL}^{-1}$ ). There was no difference in median (interquartile range) saliva ET-1 levels among CF patients (21.0 $\left.(10.9-32.3) \mathrm{pg} \cdot \mathrm{mL}^{-1}\right)$, normal subjects $(28.8(18.3-34.5)$ $\left.\mathrm{pg} \cdot \mathrm{mL}^{-1}\right)$ and COPD patients $\left(20.7(16.3-42.3) \mathrm{pg} \cdot \mathrm{mL}^{-1}\right)$ although in all groups salivary ET-1 concentration was greater than plasma ET-1 concentration.

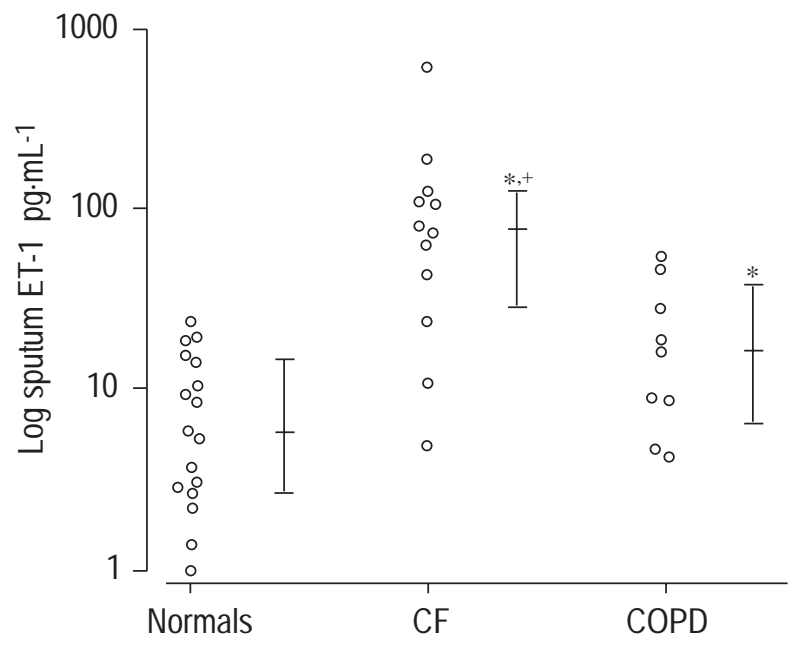

Fig. 1. - Log sputum endothelin (ET)-1 concentrations in normal subjects and patients with cystic fibrosis (CF) or chronic obstructive pulmonary disease (COPD). Vertical bars represent median and interquartile range. ${ }^{*}: \mathrm{p}<0.05$ versus normal subjects; ${ }^{+}: \mathrm{p}<0.05$ versus COPD patients.

Sputum endothelin-1. Sputum ET-1 was measured in all subjects, and was markedly elevated in CF patients compared to COPD patients and normal subjects (median (interquartile range) $77.6(29.0-122.8)$ versus $16.4(6.8-$ $38.2)$ and $6.0(2.8-14.8) \mathrm{pg} \cdot \mathrm{mL}^{-1}$ respectively), with an increase in sputum ET-1 levels in COPD patients compared with normal subjects (fig. 1). No direct correlation was found between sputum ET-1 concentration and FEV1 in CF nor between plasma and sputum ET-1 concentrations. In CF patients sputum ET-1 levels were higher than those in saliva, in normal subjects the converse was true and in COPD patients saliva and sputum levels of ET-1 were not significantly different, reflecting relative differences in sputum ET-1 rather than saliva ET-1.

\section{Discussion}

The present study demonstrated for the first time that it is possible to measure ET-1 levels in the sputum of patients with $\mathrm{CF}$, and that sputum levels of ET-1 are significantly elevated in $\mathrm{CF}$ patients compared with normal subjects. It also demonstrated a more modest increase in sputum ET-1

Table 2. - Absolute and relative sputum cell numbers for normal subjects and patients with cystic fibrosis or chronic obstructive pulmonary disease (COPD)

\begin{tabular}{lccc}
\hline & Normal subjects & Cystic fibrosis & COPD \\
\hline Absolute cell number $\times 10^{6} \cdot \mathrm{mL}^{-1}$ & & & \\
Neutrophil & $0.8(0.3-3.6)$ & $30.8(14.7-52.2)^{*,+}$ & $9.7(3.9-16.4)^{*}$ \\
Macrophage & $5.8(1.5-7.3)$ & $2.1(0.9-6.3)$ & $2.6(1.0-3.6)$ \\
Eosinophil & $0.0(0.0-0.0)$ & $0.0(0.0-0.7)$ & $0.1(0.08-0.3)^{*}$ \\
Lymphocyte & $0.03(0.0-0.2)$ & $35.2(16.0-0.3)$ & $0.05(0.0-0.1)$ \\
Total & $6.9(2.4-11.3)$ & $92(88-95)^{*}$ & $12.4(4.9-23.0)$ \\
Relative cell number \% & $19(6-35)$ & $6.5(5-10)^{*}$ & $78(74-80)^{*}$ \\
Neutrophil & $81(65-90)$ & $0.0(0-1)$ & $21(18-24)^{*}$ \\
Macrophage & $0(0-0)$ & $0.0(0-0.3)$ & $1(1-2)^{*}$ \\
Eosinophil & $2(0-4)$ & $10-1)$ \\
Lymphocyte & & & $1(0-1)$ \\
\hline
\end{tabular}

Data are presented as median (interquartile range) after exclusion of squamous and bronchial epithelial cells. $*$ : p<0.05 versus normal subjects; ${ }^{+}: \mathrm{p}<0.05$ versus COPD patients. 
in COPD patients compared to normal subjects, with significant overlap between levels in normal subjects and COPD patients. Plasma ET-1 levels are mildly elevated in CF patients compared to normal subjects, but much less so than sputum ET-1 levels. Sputum induction allowed sputum to be obtained from normal subjects for comparison. The CF patient group was sampled during a period of relative stability of symptoms, but, although they had a wide range of impairment of lung function (FEV1 19-79\% pred), none had normal lung function, and, as might be expected from their mean age, they represent a group with established disease. Similarly, the COPD group had severe impairment of lung function. Differential cell counts showed prominent sputum neutrophilia in $\mathrm{CF}$, and similar but less pronounced neutrophilia in the COPD group.

The presence of ET-1 in sputum and saliva at higher concentrations than in plasma in all three groups suggests that ET-1 is produced or released locally within the respiratory tract, with an increase in production or release in the lower respiratory tract in $\mathrm{CF}$ and, to a lesser extent, COPD. The factors leading to this increase in ET-1 concentration in CF and COPD are not known. ET-1 is present in the normal lung, and ET-1 immunoreactivity has been demonstrated in airway epithelia and submucosal glands throughout the lung [9], as well as in airway smooth muscle and parasympathetic ganglia in the airways [10]. Release of ET-1 has been described from bronchial epithelial cells [3], neuroendocrine cells and human macrophages [11], and although human neutrophils can convert big ET to ET-1 [12], there is no evidence that neutrophils can synthesize ET-1 de novo. Increased ET-1 levels have been described in bronchial biopsy samples [13] and bronchoalveolar lavage (BAL) fluid [14] in asthma, but not, to the authors' knowledge, in BAL fluid, biopsy samples or sputum in COPD or CF.

Spontaneous sputum was obtained from the CF subjects, and from seven (of nine) of the COPD group. Normal subjects do not produce spontaneous sputum, and sputum induction was therefore performed in these subjects and the two COPD subjects who could not produce spontaneous sputum. While it is accepted that spontaneous and induced sputum are not identical in all respects, and that formal comparisons of sputum ET-1 levels between spontaneous and induced sputum have not been reported, it has been demonstrated that total cell numbers and concentrations of soluble factors in sputum are in good agreement between spontaneous and induced sputum [15], with better cell viability in induced sputum samples. The same study found increased numbers of squamous cells in spontaneous sputum, but this should be minimized by sputum plug separation to limit salivary contamination. The fact that sputum ET-1 levels were higher in sputum than saliva in $\mathrm{CF}$ suggests that salivary contamination is not responsible for the elevated levels of ET-1 in CF sputum. Sputum samples from CF subjects were treated with DNAse to facilitate processing of the unusually viscous sputum produced in CF, and, while DNAse was not used for samples obtained from normal subjects or COPD patients, the possibility of an effect of DNAse on the ET-1 assay was investigated and it was found that DNAse did not alter the standard curve for the assay.

Saliva levels of ET-1 were higher than plasma levels in all three groups, and, although immunoreactive staining of ET-1 has been demonstrated in rat parotid gland and human saliva [16], no physiological explanation for this has been offered.

ET-1 is a potent bronchoconstrictor in human bronchi in vitro [17] and it has previously been demonstrated that inhaled ET-1 has bronchoconstrictor activity in asthma, with bronchial hyperreactivity to ET-1 in asthmatics compared with normal subjects [4], supporting a putative role for ET-1 as a mediator in asthma. In CF, bronchial hyperresponsiveness to methacholine has been demonstrated in $50-77 \%$ of patients [18] and, although the response to bronchodilators is less predictable than in asthma, many patients with $\mathrm{CF}$ are treated with bronchodilators [1]. Like asthma, COPD is characterized by airflow obstruction, although, unlike asthma, this is generally poorly reversible; bronchial hyperreactivity is a less consistent finding. While the mechanisms of airway narrowing in asthma, COPD and CF may differ, the presence of a bronchoconstrictor with the potency of ET-1 at increased concentration in the sputum of patients with $\mathrm{CF}$ and COPD requires further investigation.

The activity of a number of inflammatory and growth factors has been described in CF lungs. Among other cytokines, TNF- $\alpha$ and its receptor [19] are elevated in BAL fluid in CF. In normal lung tissue, TNF- $\alpha$ increases the expression of ET-1 in bronchial epithelial cells [20], and TNF- $\alpha$ release is itself increased by ET-1 [7]. ET-1 has been shown to be mitogenic for airway smooth muscle by a number of mechanisms both in vitro and in vivo [21] in animal studies. The precise nature of the various interactions between growth factors is by no means clear, and the cellular sources and identity of other potential mediators of peribronchial fibrosis and airway remodelling are not known.

The presence of endothelin-1 in increased concentration in cystic fibrosis airways suggests that further investigation of its role in bronchoconstriction and airway remodelling is justified and potential interactions of endothelin-1 with other growth factors in cystic fibrosis remain to be clarified.

\footnotetext{
Acknowledgements. The authors would like to acknowledge the assistance of J.J. Morton (University of Glasgow Department of Medicine and Therapeutics) who performed the endothelin assays.
}

\section{References}

1. Cropp G. The effectiveness of bronchodilators in cystic fibrosis. Am J Med 1996; 100: 19S-29S.

2. Leigh M, Kylander J, Yankaskas J, Boucher R. Cell proliferation in bronchial epithelium and submucosal glands of cystic fibrosis patients. Am J Respir Cell Mol Biol 1995; 12: 605-612.

3. Mattoli S, Mezzetti M, Riva G, Allegra L, Fasoli A. Specific binding of endothelin on human bronchial smooth muscle cells in culture and secretion of endothelinlike material from bronchial epithelial cells. Am J Respir Cell Mol Biol 1990; 3: 145-151.

4. Chalmers G, Little S, Patel K, Thomson N. Endothelin-1induced bronchoconstriction in asthma. Am J Respir Crit Care Med 1997; 156: 382-388. 
5. Noveral J, Rosenberg S, Anbar R, Pawlowski N, Grunstein M. Role of endothelin-1 in regulating proliferation of cultured rabbit airway smooth muscle cells. $\mathrm{Am}$ J Physiol 1992; 263: L317-L324.

6. Murlas C, Gulati A, Singh G, Najmabadi F. Endothelin-1 stimulates proliferation of normal airway epithelial cells. Biochem Biophys Res Commun 1995; 212: 953-959.

7. Chanez P, Vignola A, Albat B, et al. Involvement of endothelin in mononuclear phagocyte inflammation in asthma. J Allergy Clin Immunol 1996; 98: 412-420.

8. Marini M, Carpi S, Bellini A, Patalano F, Mattoli S. Endothelin-1 increases fibronectin expression in human bronchial epithelial cells. Biochem Biophys Res Commun 1996; 220: 896-899.

9. Marciniak S, Plumpton C, Barker P, Huskisson N, Davenport A. Localisation of immunoreactive endothelin and proendothelin in the human lung. Pulm Pharmacol 1992; 5: 175-182.

10. McKay K, Black J, Diment M, Armour C. Functional and autoradiographic studies of endothelin-1 and endothelin2 in human bronchi, pulmonary arteries, and airway parasympathetic ganglia. J Cardiovasc Pharmacol 1991; 17: 206-209.

11. Ehrenreich H, Anderson R, Fox C, et al. Endothelins, peptides with potent vasoactive properties are produced by human macrophages. J Exp Med 1990; 172: 17411748.

12. Sessa W, Kaw S, Heeker M, Vane J. The biosynthesis of endothelin-1 by human polymorphonuclear leukocytes. Biochem Biophys Res Commun 1991; 174: 613-618.

13. Springall D, Howarth P, Counihan H, Djukanovic R,
Holgate S, Polak J. Endothelin immunoreactivity of airway epithelium in asthmatic patients. Lancet 1991; 337: 697-701.

14. Redington A, Springall D, Ghatei M, et al. Endothelin in bronchoalveolar lavage fluid and its relation to airflow obstruction in asthma. Am J Respir Crit Care Med 1995; 151: 1034-1039.

15. Pizzichini M, Popov T, Efthimiadis A, et al. Spontaneous and induced sputum to measure indices of airway inflammation in asthma. Am J Respir Crit Care Med 1996; 154: 866-869.

16. Lam H, Takahashi K, Ghatei M, Suda K, Kanse S, Bloom S. Presence of immunoreactive endothelin in human saliva and rat parotid gland. Peptides 1991; 12: 883-885.

17. Nally J, McCall R, Young L, Wakelam M, Thomson N, McGrath J. Mechanical and biochemical responses to endothelin-1 and endothelin-3 in human bronchi. Eur $J$ Pharmacol 1994; 288: 53-60.

18. Sanchez I, Powell R, Chernick V. Response to inhaled bronchodilators and nonspecific airway hyperreactivity in children with cystic fibrosis. Paediatr Pulmonol 1992; 14: 52-57.

19. Bonfield T, Panuska J, Konstan M, et al. Inflammatory cytokines in cystic fibrosis lungs. Am J Respir Crit Care Med 1995; 152: 2111-2118.

20. Shah A, Church M, Holgate S. Tumour necrosis factor alpha: a potential mediator of asthma. Clin Exp Allergy 1995; 25: 1038-1044.

21. Noguchi S, Kashihara Y. Alterations of airway smooth muscle structure in endothelin-1-infused guinea-pigs in vivo. Am J Respir Crit Care Med 1996; 153: A843. 